\title{
Identification of a familial cleidocranial dysplasia with a novel RUNX2 mutation and establishment of patient-derived induced pluripotent stem cells
}

\author{
Atsuko Hamada ${ }^{1} \cdot$ Hanae Mukasa ${ }^{1,4} \cdot$ Yuki Taguchi $^{1}$ - Eri Akagi ${ }^{1}$. Fumitaka Obayashi ${ }^{1} \cdot$ Sachiko Yamasaki ${ }^{1}$. \\ Taku Kanda $^{1} \cdot$ Koichi Koizumi $^{2} \cdot$ Shigeaki Toratani $^{2} \cdot$ Tetsuji Okamoto $^{2,3}$
}

Received: 11 September 2021 / Accepted: 31 October 2021 / Published online: 15 November 2021

(c) The Author(s) 2021

\begin{abstract}
Cleidocranial dysplasia (CCD) is an autosomal dominant hereditary disease associated with the gene RUNX2. Diseasespecific induced pluripotent stem cells (iPSCs) have emerged as a useful resource to further study human hereditary diseases such as CCD. In this study, we identified a novel CCD-specific RUNX2 mutation and established iPSCs with this mutation. Biopsies were obtained from familial CCD patients and mutation analyses were performed through Sanger sequencing and next generation sequencing. CCD-specific human iPSCs (CCD-hiPSCs) were established and maintained under completely defined serum, feeder, and integration-free condition using a non-integrating replication-defective Sendai virus vector. We identified the novel mutation $R U N X 2 \_c .371 C>G$ and successfully established CCD-hiPSCs. The CCD-hiPSCs inherited the same mutation, possessed pluripotency, and showed the ability to differentiate the three germ layers. We concluded that $R U N X 2 \_c .371 C>G$ was likely pathogenic because our results, derived from next generation sequencing, are supported by actual clinical evidence, familial tracing, and genetic data. Thus, we concluded that hiPSCs with a novel CCD-specific $R U N X 2$ mutation are viable as a resource for future studies on CCD.
\end{abstract}

Keywords RUNX2 $\cdot$ Mutation · Dysplasia $\cdot$ Cleidocranial $\cdot$ iPSC

Atsuko Hamada and Hanae Mukasa contributed equally to this work.

Atsuko Hamada

hamaco@hiroshima-u.ac.jp

Tetsuji Okamoto

tetsuok@hiroshima-u.ac.jp

1 Department of Molecular Oral Medicine and Maxillofacial Surgery, Division of Applied Life Science, Graduate Institute of Biomedical and Health Science, Hiroshima University, 1-2-3, Kasumi, Minami-ku, Hiroshima-city, Hiroshima 734-8553, Japan

2 Department of Molecular Oral Medicine and Maxillofacial Surgery, Graduate School of Biomedical and Health Science, Hiroshima University, Hiroshima, Japan

3 School of Medical Sciences, The University of East Asia, Shimonoseki, Yamaguchi 751-8503, Japan

4 Present Address: Mukasa Dental Clinic, Kanagawa, Japan

\section{Introduction}

Cleidocranial dysplasia (CCD [MIM 119600]) was first described as cleidocranial dysostosis by Marie and Sainton [1]. The incidence of CCD is estimated to be one per one million people. While familial cases of CCD are inherited in an autosomal dominant manner with marked phenotypic variability, many cases of this disorder appear to be sporadic [2]. CCD is characterized by skeletal anomalies such as delayed closure of the cranial sutures, hypoplastic clavicles, short stature, and multiple dental abnormalities, including delayed eruption of permanent teeth and existence of supernumerary teeth. The delay of permanent teeth replacement or lack of eruption of permanent dentition leads to a lack of vertical growth of the maxilla, resulting in horizontal overgrowth of the mandible [3]. To obtain normal occlusion, dental management of CCD patients should be initiated under early diagnosis [4].

The gene associated with CCD is runt-related gene 2 (RUNX2) (previously called Cbfa1) [5-7], which is located on chromosome $6(6 \mathrm{p} 21)$. RUNX2 is a transcription factor 
that belongs to the RUNX family, which consists of RUNX1, RUNX2, and RUNX3. RUNX2 induces the proliferation of suture mesenchymal cells and their commitment to osteoblast-lineage cells by increasing the expression of hedgehog, $F G F, W N T$, and $P T C H$ signaling genes [8]. In chondrocytes, RUNX2 acts on the differentiation of pre-hypertrophic chondrocytes into hypertrophic chondrocytes [9-12]. The runt homology domain (RHD) of RUNX2, is composed of 128 amino acids and is responsible for heterodimerization with $\mathrm{Cbfb}$, a cofactor that enhances the DNA affinity of the subunit $[13,14]$. A nine-amino acid sequence (PRRHRQKLD) located behind the RHD, behaves as a nuclear localization signal (NLS) [15]. Both the RHD and the NLS have been conserved in all RUNX proteins across the species. This evolutionary conservation of the RHD and NLS indicates that most missense mutations involving the runt domain are likely to affect protein function and lead to haploinsufficiency [16]. In CCD patients, many monoallelic mutations of $R U N X 2$ have been identified, including deletion, missense, nonsense, and frameshift mutations [2, 17, 18]. Most of these mutations are clustered in the N-terminal RHD with several positions emerging as mutational hotspots [2]. Of these, arginine residues are thought to be particularly prone to mutagenic events through $\mathrm{CpG}$-directed methylation [16]. The missense mutation RUNX2_R225Q, which has been reported in multiple cases worldwide, is possibly the most frequently found mutation in CCD [19-21]. The use of CCD disease-specific human induced pluripotent stem cells (CCD-hiPSCs) with RUNX2_R225Q in disease modeling has also been previously reported by us [22]. With the aim of further understanding human hereditary diseases, diseasespecific iPSCs were first established by Okada et al. [23]. Examples of iPSC use include the modeling of chondrodysplasias in vitro and drug dispositioning using diseasespecific iPSCs [24]. In this study, we identified the novel mutation RUNX2_c.371C $>\mathrm{G}$ in familial $\mathrm{CCD}$ patients and established CCD-specific hiPSCs bearing this novel RUNX2 mutation.

\section{Material and methods}

\section{Patient information}

The patient (F4) (Fig. 1A), an 8-year-old girl, visited pediatric dentistry in our hospital with the main complaint of malocclusion. According her medical history, she had been clinically diagnosed with CCD by her pediatrician during infancy. She was referred to our department at 10-yearold and was diagnosed with CCD according to criteria, which included delayed closure of the cranial sutures, presence of supernumerary teeth, and non-eruption of permanent teeth (Fig. 1B). The patient underwent extraction of supernumerary teeth and odontoma, pulling of unpacked permanent teeth, and orthognathic surgery under general anesthesia. The patient's younger brother (F5) (Fig. 1A) was also clinically diagnosed with CCD and introduced to our department because of malocclusion. He underwent extraction of supernumerary teeth and pulling of unpacked permanent teeth under local anesthesia. The patient's mother (F3) (Fig. 1A) had started orthodontic treatment in our hospital a few years ago and was clinically diagnosed with CCD (Fig. 1B). She had undergone several tooth extractions in another hospital before her first visit to our hospital making the details of her treatment unavailable. The patient's grandfather (F2) (Fig. 1A) seemed to exhibit a skeletal mandibular protrusion, and her great-grandmother (F1) (Fig. 1A) seemed to have several supernumerary teeth. Although they (F1 and F2) were not diagnosed in our hospital, they were most likely suffering from CCD. The pedigree and phenotype are shown in Fig. 1A and 1C.

\section{Mutation analysis with Sanger sequencing and next generation sequencing (NGS)}

The patient's genomic DNA was isolated from blood samples, dental pulp cells (DPCs) and CCD-DPC-hiPSCs with a QIAamp® DNA mini kit (Qiagen, Valencia, CA) according to the manufacturer's protocol. To identify RUNX2 mutations, Sanger sequencing was performed with the primers we described previously [22]. The PCR product was purified using a Wizard@ SV Gel and PCR Clean-Up System (Promega, Madison, WI) and sequenced directly with a CEQ8000 Beckman system (Beckman-Coulter, Brea, CA).

To further search for pathogenic mutations in genes other than RUNX2 in this CCD family, targeted resequencing was performed with a MiSeq using a TruSight one panel (Illumina, San Diego, CA, USA), which is designed to comprehensively cover more than 4800 genes involved in diseases. Sequencing was done according to the manufacturer's instructions using DNA derived from blood samples and dental pulp samples from F3 and F5. Data analysis was performed using the Illumina VariantStudio 3.0.

\section{Isolation of dental pulp cells (DPCs) and induction of CCD-DPC-hiPSCs}

Isolation of DPCs and induction of DPC-hiPSCs were performed as described previously [25]. Briefly, DPCs were cultured in RD6F serum-free medium [26] for 14 days at $37{ }^{\circ} \mathrm{C}$ in a humidified atmosphere of $95 \%$ air $/ 5 \%$ $\mathrm{CO}_{2}$. Then, DPCs at a density of $1 \times 10^{5}$ cells were infected with SeVdp (KOSM) [27], which does not integrate into the host genome, at a multiplicity of infection of 6 in a gelatin (Millipore, Billerica, MA)-coated 12-well plate. After overnight culture the infected cells were trypsinized, 
Fig. 1 Pedigree and phenotype of familial Cleidocranial dysplasia (CCD). A Pedigree of familial CCD was shown. B Cephalometric radiogram and panotamic X-ray photos of F4 and F5. (C) F3, F4, and F5 shared phenotypes and genotype. The phenotype of cranial and clavicle both in F1 and F2 were not detected because of difficulties in visiting our hospital

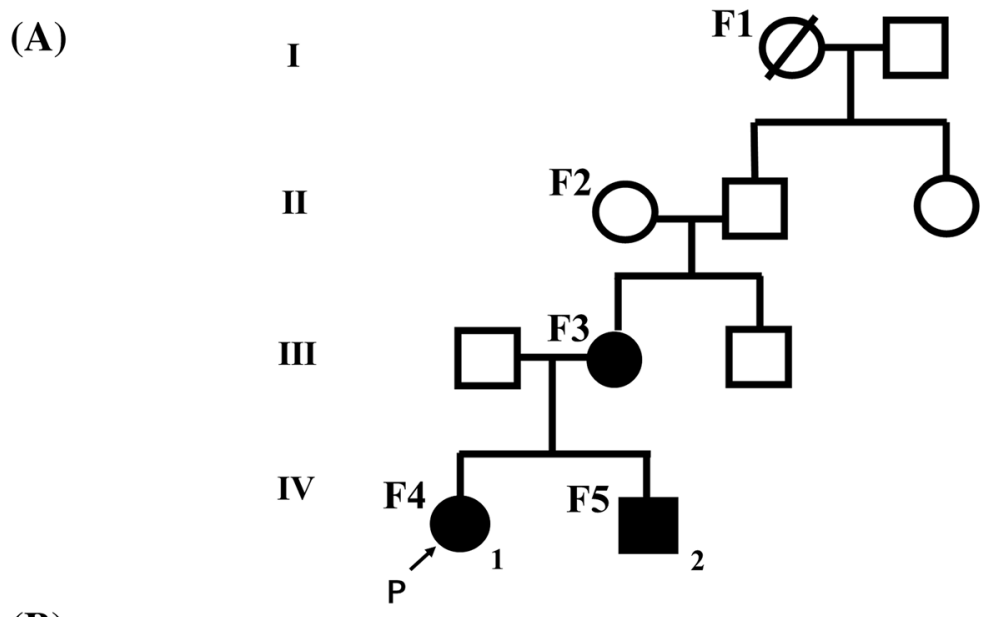

(B)
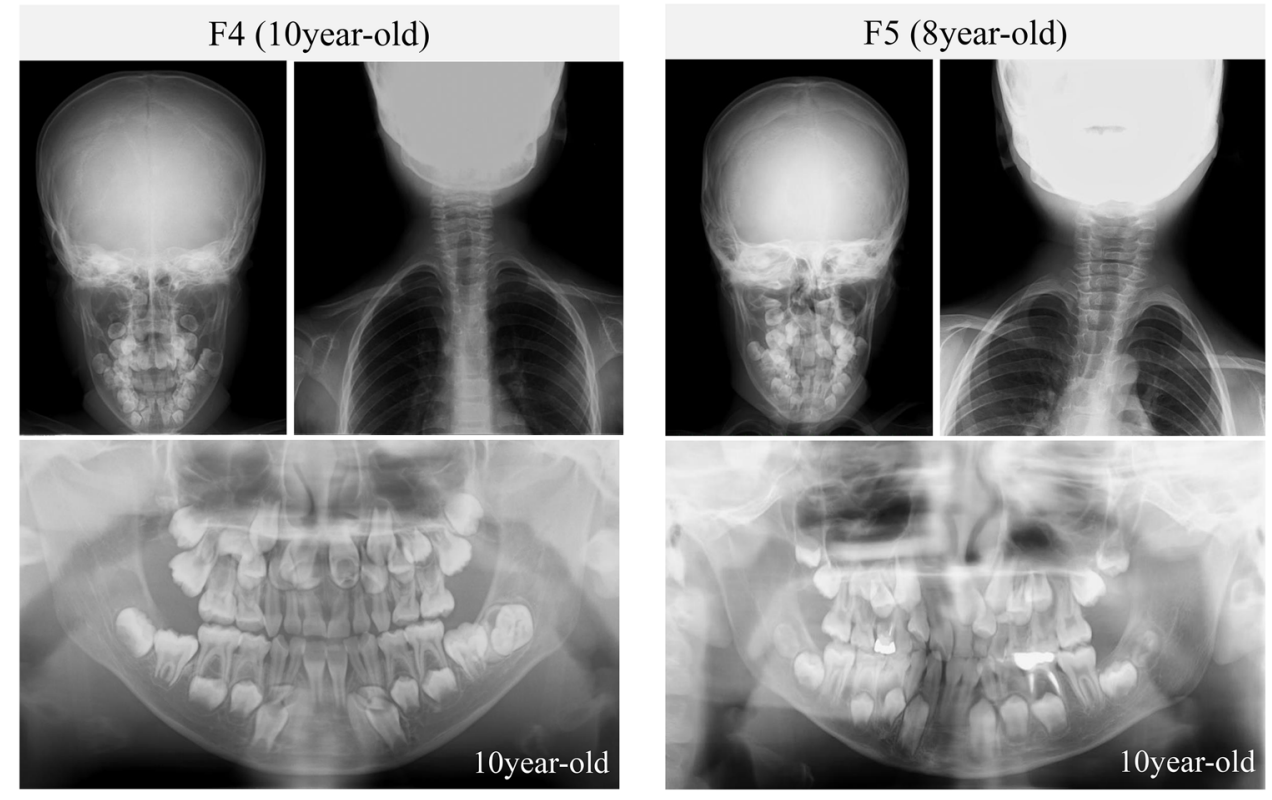

(C)

\begin{tabular}{|c|c|c|c|c|}
\hline \multirow{2}{*}{ Patient } & \multicolumn{3}{|c|}{$\begin{array}{r}\text { Phenotype } \\
\end{array}$} & \multirow{2}{*}{$\frac{\text { Genotype }}{R U N X 2 \_c .371 \mathrm{C}>\mathrm{G}}$} \\
\hline & $\begin{array}{l}\text { delay closure } \\
\text { of fontanelle }\end{array}$ & $\begin{array}{c}\text { hypoplastic } \\
\text { clavicle }\end{array}$ & $\begin{array}{c}\text { dental } \\
\text { anomallies }\end{array}$ & \\
\hline F1 & & & + & \\
\hline F2 & & & + & \\
\hline F3 & - & + & + & + \\
\hline F4 & - & + & + & + \\
\hline F5 & - & + & + & + \\
\hline
\end{tabular}

seeded at a density of $1.0 \times 10^{4}$ cells/well onto a fibronectin $\left(2 \mu \mathrm{g} / \mathrm{cm}^{2}\right)$ (Sigma-Aldrich, St. Louis, MO)-coated 6-well plate with serum-free hESF9 medium [28-30], and incubated at $38{ }^{\circ} \mathrm{C}$ under the conditions described above. Approximately 14 days after infection, human embryonic stem cell (ESC)-like colonies were mechanically picked, and subsequently expanded on fibronectin-coated dishes in hESF9 with TGF- $\beta 1(2 \mathrm{ng} / \mathrm{mL})$ or activin A $(10 \mathrm{ng} / \mathrm{mL})$ at $37{ }^{\circ} \mathrm{C}$ in $95 \%$ air $/ 5 \% \mathrm{CO}_{2}$ as reported previously [31].

\section{Characterization of CCD-DPC-hiPSCs in vitro}

The hiPSCs were characterized as described previously [25, 32]. Briefly, to confirm the pluripotency of the 
CCD-DPC-hiPSCs, reverse transcription-polymerase chain reaction (RT-PCR) of pluripotent markers (OCT, NANOG, $S O X 2$, and REX1) was performed using OnePCR ${ }^{\mathrm{TM}}$ (GeneDireX, Inc. Taoyuan, Taiwan). Next, to determine the in vitro differentiation capacity of the CCD-DPC-hiPSCs, we performed an embryoid body (EB) assay. Differentiated cells were fixed, stained with antibodies (against $\beta$-III tubulin, MAP, $\alpha$-smooth muscle actin, and $\alpha$-fetoprotein), and visualized under a Zeiss inverted LSM 700 confocal microscope (Carl Zeiss GmbH, Jena, Germany).

\section{Chondrocyte induction under completely serum-free conditions}

The hiPSCs were detached with TrypLE/ EDTA, and $1 \times 10^{5}$ cells per well were in seeded in a low attachment $U$ bottom prime surface 96-well plate in hESF6 without FGF2 and heparin and cultured for 7 days to make EBs. Then, 5-7 EBs were transferred to a gelatin-coated $35 \mathrm{~mm}$ dish. After approximately 7 days, mesenchymal stem-like cells had grown out from the EBs and spread to confluence in the dish. To remove the EB mass, the detached cells were filtered through a $70 \mu \mathrm{l}$ filter. After several passages through the filter using hESF9 with FGF2 and heparin, the cells were analyzed with FACS (Sony, cell sorter, Tokyo, Japan) using anti-MSC marker (CD73, CD90, CD105) antibodies (Miltenyi Biotec) on 4th week. The induced MSCs were seeded on a fibronectin-coated $60 \mathrm{~mm}$ dish at a concentration of $1.0 \times 10^{6}$ cells per dish with hESF9. Chondrogenic medium consisted of hESF6f as a base medium supplemented with Wnt3A (10 ng/ml) (R\&D, Minneapolis, MN) and activin (10 ng/ml) (R\&D) for 4.5-4.7 weeks and then BMP2 (50 $\mu \mathrm{g} / \mathrm{ml})(\mathrm{R} \& \mathrm{D})$, TGF $\beta 1$ (10 $\mathrm{ng} / \mathrm{ml})(\mathrm{R} \& \mathrm{D})$, GDF5 (10 ng/ml) (Origene MD, USA), and FGF2 (10 ng/ml) (R\&D) for 4.7-10 weeks. On the 6th week, the cells were detached in a sheet using a p-1000 pipet tip, transferred to a $15 \mathrm{ml}$ tube, centrifuged at $200 \times g$ for $5 \mathrm{~min}$ (KUBOTA corporation, Tokyo, Japan), and kept in an incubator at $37{ }^{\circ} \mathrm{C}$ in a humid atmosphere of $95 \%$ air $/ 5 \% \mathrm{CO}_{2}$. The tube was centrifuged at $7 \times g$ for 5 min each day over $6-10$ weeks. This protocol was a modified version of the process for chondrogenic differentiation of hiPSCs reported by Yamashita et al. [33]. At 10th week, cartilages were implanted in the dorsal flank of SCID (CB17/Icr-Prkdcscid/CrlCrlj) mice for more 4 weeks. After fixation with 4\% PFA and decalcification with ethylenediaminetetraacetic acid, each slice was stained with Alcian blue/PAS and Safranin O.

\section{Results}

Using Sanger sequencing, RUNX2_c.371C $>G$ was detected in individuals F3, F4, and F5 (Fig. 2). To screen for other pathogenic mutations affecting $\mathrm{CCD}$, we performed
NGS on an MiSeq using a TruSight one panel for familial CCD and detected three shared mutations, including, RUNX2_c.371C $>$ G,SIL1_c.617T >A, and SOX9_c.724A>C. SIL1 is the gene responsible for autosomal recessive Marinesco-Sjögren syndrome (MIM 608005). Though SIL1_c.617T $>A$ was predicted to be 'disease-causing' in silico, the detected mutation was heterozygous, indicating non-pathogenicity. SOX9, the Sox family of transcriptional regulators, is known to function during chondrocyte differentiation, and its deficiency leads to skeletal malformation [34]. However, the detected mutation, SOX9_c.724A >C_p. $\mathrm{K} 242 \mathrm{Q}$, was not located in the DNA binding domain. Thus, we eliminated the SIL1_c.617T $>A$ and SOX9_c.724A $>C$ mutations from the group of mutations considered pathogenic. The base substitution 'c.371C $>\mathrm{G}$ ' in $R U N X 2$, which was predicted to be 'disease-causing' by Mutation Taster, 'probably damaged' by PolyPhen-2, and 'deleterious' by the SIFT software, indicates a substitution of serine to tryptophan at codon 124, p.S124W, which is in the RHD. Based on this information, we predicted that RUNX2_c.371C $>$ G_p.S124W was a 'likely pathogenic' mutation for CCD. However, RUNX2_c.371C $>$ G_p. S124W was not found in Togo Var or Exome Variant Server, whereas in dbSNP and Clinvar, this mutation was submitted as NM_001024630.4(RUNX2):c.371C > G (p.Ser124Trp) in January 2021 and classified as a variant of uncertain significance (VUS). However, as far as we have investigated, clinical case of CCD with this mutation has not been reported anywhere.

CCD-derived disease-specific hiPSCs inherited the RUNX2 mutation c. 371C $>$ G (Fig. 3), exhibiting ESClike colonies in phase contrast images (Fig. 4A). The cells were positive for $O C T, N A N O G, S O X 2$, and REX1 in PCR analyses (Fig. 4B). In vitro, these cells differentiated into three germ layers: the endoderm, mesoderm, and ectoderm (Fig. 4C). Together, these properties demonstrate that the cells were pluripotent and had the ability to differentiate.

\section{Discussion}

The algorithms of SIFT, PolyPhen-2, and Align-GVGD, etc. were recently developed to predict the effects of missense changes on protein structures [35]. According to the algorithms, NM_001024630.4(RUNX2): c.371C >G (p.Ser124Trp) was predicted 'likely pathogenic' because the serine residue was moderately conserved and there was a large physicochemical difference between serine and tryptophan. Since Yoshida et. al. reported that the mutations (151 fs, R179X, R176W, K204N, T206I, and $\mathrm{R} 211 \mathrm{~W}$ ) in RHD domain showed no DNA binding [2], we predicted the detected mutation c.371C $>$ G_p.S124W, which located in RHD domain, also lacks DNA binding 
Fig. 2 Direct sequencing of $R U N X 2$ in familial Cleidocranial dysplasia (CCD). The results of direct sequencing of $R U N X 2$ exon 3 are shown. The RUNX2_c.371C $>\mathrm{G}$ were detected in F3-F5 (A-C)
(A) F3

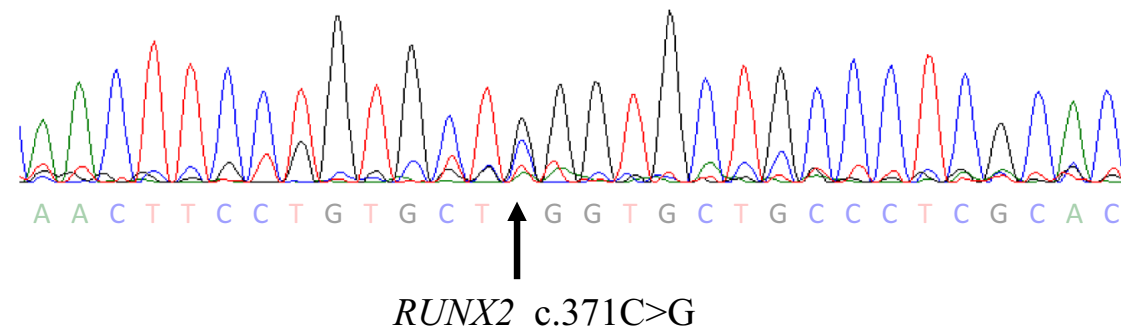

(B) F4

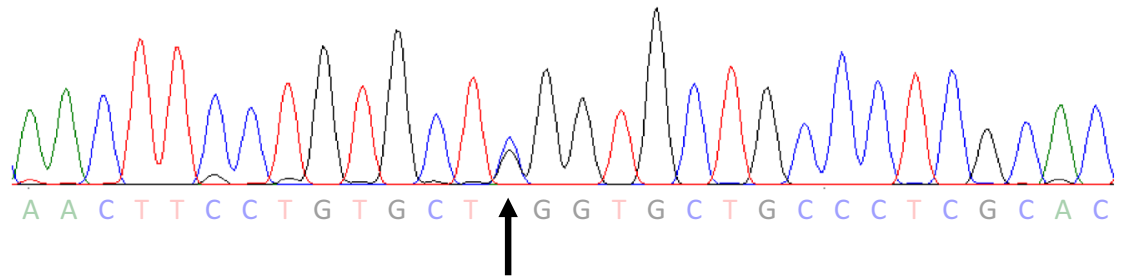

(C) F5

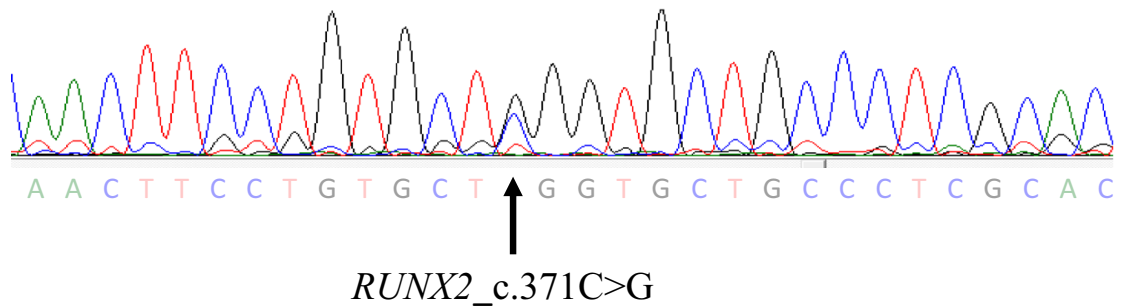

(A)

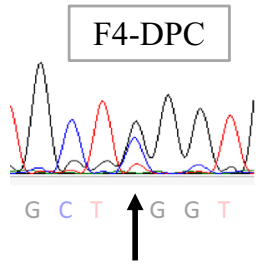

$R U N X 2 \_$c.371C $>\mathrm{G}$

(B)

F4-DPC-CCD-hiPSC

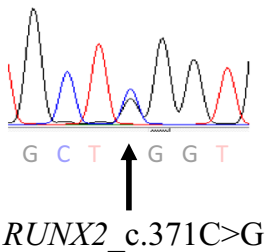

(C)

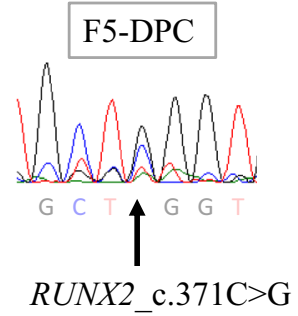

(D)

\section{F5-DPC-CCD-hiPSC}

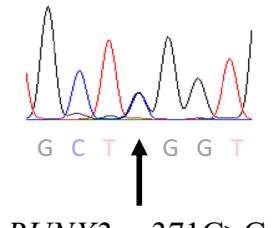

Fig. 3 Direct sequencing of $R U N X 2$ in dental pulp cells (DPCs) and DPC-CCD-hiPSCs. The mutation in DPC (A and $\mathbf{C})$ were hereditary in DPC-CCD-hiPSC (B and D) respectively

ability. As this variant had not been reported in individuals with CCD-associated phenotypes in the literature, it was classified as a VUS. In this report, we identify, for

the first time, the RUNX2 mutation c.371C $>$ G_p.S124W in a CCD family.

The CCD family reported in this study exhibited the common phenotypes of open suture, hypoplastic clavicles, and supernumerary teeth. Although the patients showed no delay in fontanelle closure, in general, our results matched those of a previous study [2]. Short stature was only observed in female patients (F3 and F4). This finding contradicts those of the animal model report by Choi et al., in which male C57BL/6 mice heterozygous for Runx 2 with a C-terminal deletion exhibited a significantly lower growth than wild type mice, while the equivalent female heterozygotes showed normal weight [36].

Patients F4 and F5 had 8 and 10 supernumerary teeth, respectively. Previous studies have reported that in patients with $\mathrm{CCD}$, the number of supernumerary teeth ranged from 0 to 21 , and that these teeth were frequently found as maxillary incisors and mandibular premolars $[37,38]$. Understanding the relationship between the mutations in RUNX2 and CCDassociated phenotypes, including the final height of patients or the number of supernumerary teeth, may enable the early initiation of effective treatments, such as therapy with recombinant human growth hormone at an appropriate stage. In previous study, we reported that the cartilage tissues derived from 3-dimentional cultured-CCD-hiPSCs, which established from DPC of CCD patient (RUNX2_R225Q), indicated lack 
(A)
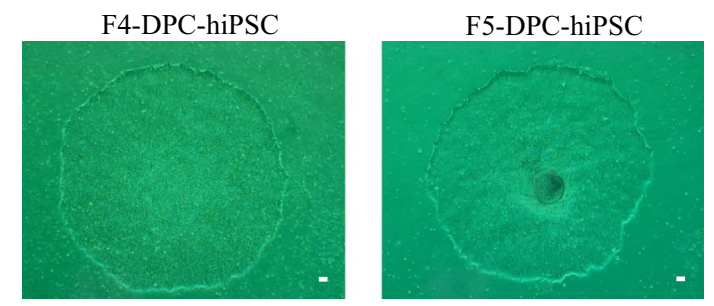

(B)

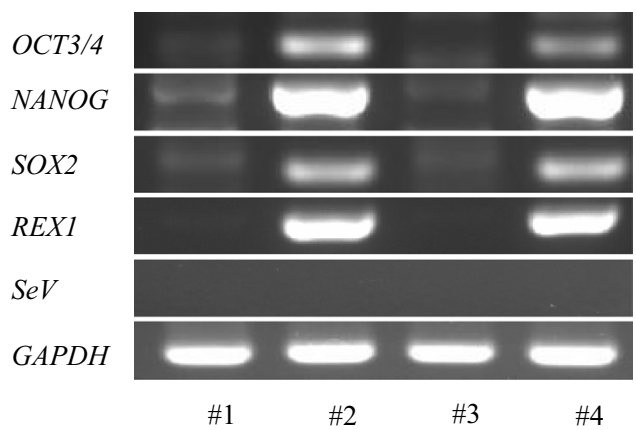

(C)
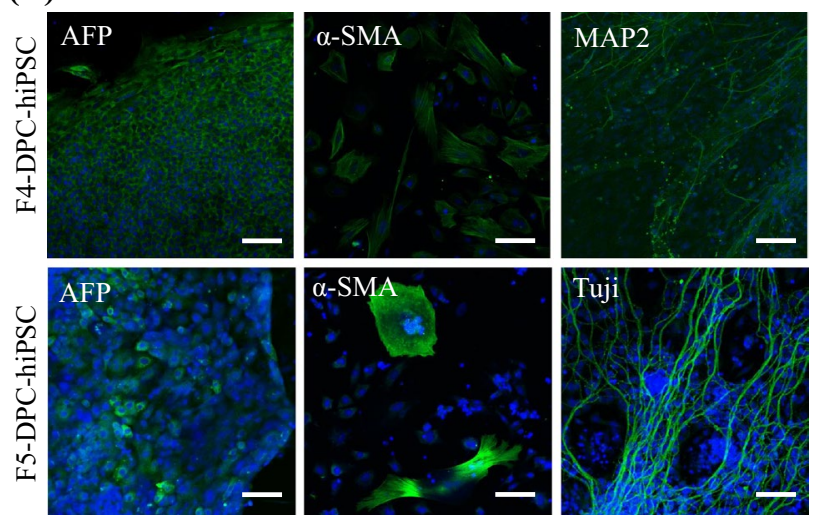

Fig. 4 Characterization of DPC-CCD-hiPSCs. A Phase contrast images of DPC-CCD-hiPSCs (F4-DPC-iPS; clone 6 at passage 21, F5-DPC-iPS; clone 3 at passage 21). B Gene expression of pluripotent markers by RT-PCR (\#1; F4-DPC, \#2; F4-DPC-CCD-iPSC, \#3; F5-DPC, \#4; F5-DPC-CCD-iPSC). Although NANOG and SOX2 were weakly detected before reprogramming, OCT3/4, NANOG, $S O X 2$, and REX1 were strongly expressed after reprogramming. $\mathrm{SeVdp}$ was not detected under any conditions. C Immunofluorescence staining of differentiation markers in DPC-CCD-hiPSCs after 3 week of differentiation in vivo ( $\beta$-III tubulin, MAP2, smooth muscle actin (SMA), and alpha fetoprotein (AFP)). Each bar indicates $100 \mu \mathrm{m}$ in length

of cartilaginous elements [22]. Furthermore, after 4 weeks inoculation of cartilage derived from CCD-hiPSCs in dorsal flank of SCID (CB17/Icr-Prkdcscid/CrlCrlj) mice, the cartilage exhibited delayed ossification compared from those of control (Supplementary Figure). These findings might suggest that the mutation of the RUNX2 in the CCD inhibits proliferation and differentiation of hypertrophic chondrocytes or osteoblast-lineage indicating that the CCD-hiPSCs model could mimic some part of CCD pathology. On the other hand, it has been reported that regenerative medicine using anti-uterine sensitization-associated gene-1, which exerts an antagonistic effect against RUNX2 during tooth development, could control the tooth number $[39,40]$. Using CCD-iPSC-derived cell types, we will be able to identify specific roles for RUNX2 in chondrocyte development, reveal disease occurring, and identify new therapeutic targets that would complement strategies to modulate the signaling properties of the RUNX2.

In conclusion, we report a novel mutation, RUNX2_c.371C $>$ G_p.S124W, in Japanese familial CCD. Based on the clinical evidence and preliminary data mining using online tools and software, RUNX2_c.371C $>$ G_p. $\mathrm{S} 124 \mathrm{~W}$ is a 'likely pathogenic' mutation for CCD. Based on previous findings and those of the current study, analyses of RUNX2 mutations using CCD-derived iPS cell lines may contribute to the development of regenerative therapies for CCD.

Acknowledgements We would like to thank all individuals who participated in this study. We deeply grateful Drs. M. Nakanishi, M. Ohtaka (TOKIWA-Bio, Inc., Tsukuba, Ibaraki, Japan and National Institute of Advanced Industrial Science and Technology (AIST), Tsukuba, Ibaraki, Japan), and K. Nishimura (Laboratory of Gene Regulation, Faculty of Medicine, University of Tsukuba, Tsukuba, Ibaraki, Japan) for their generous providing SeVdp (KOSM). We gratefully acknowledge Dr. J. Denry Sato for his helpful advice. This research was partially supported by the Grants-in-Aid for Scientific Research (B) to T. O. (Grant number: 18H03000), Grant-in-Aid for Young Scientists to A. H. (19K191980A), and Grant-in-Aid for Scientific Research (C) to S. Y. (18K09723) from the Japanese Ministry of Education, Culture, Sports, Science and Technology. This work was carried out in part at the Natural Science Center for Basic Research and Development, Hiroshima University.

Author contributions AH: data curation; formal analysis; funding acquisition; validation; visualization; writing-original graft. HM: data curation; visualization. YT: visualization. EA: Data curation; visualization. FO: data curation; visualization. SY: conceptualization; methodology; Project administration; funding acquisition. TK: methodology. KK: methodology. ST: supervision; funding acquisition. TO: conceptualization; methodology; project administration; supervision; funding acquisition; writing-review and editing.

Funding This research was financially supported by the Grants-in-Aid for Scientific Research (B) to T. O. (Grant number: 18H03000), Grantin-Aid for Young Scientists to A. H. (19K191980A), and Grant-in-Aid for Scientific Research (C) to S. Y. (18K09723) from the Japanese Ministry of Education, Culture, Sports, Science and Technology.

\section{Declarations}

Conflict of interest The authors declare no conflict of interest.

Ethics statement This study was approved by the Ethics Committee of Human Genome/Gene Analysis Research at Hiroshima University (approval number: hi-72 \& hi-58). All participants gave their informed consent prior to their inclusion in this study.

Open Access This article is licensed under a Creative Commons Attribution 4.0 International License, which permits use, sharing, adaptation, distribution and reproduction in any medium or format, as long as you give appropriate credit to the original author(s) and the source, 
provide a link to the Creative Commons licence, and indicate if changes were made. The images or other third party material in this article are included in the article's Creative Commons licence, unless indicated otherwise in a credit line to the material. If material is not included in the article's Creative Commons licence and your intended use is not permitted by statutory regulation or exceeds the permitted use, you will need to obtain permission directly from the copyright holder. To view a copy of this licence, visit http://creativecommons.org/licenses/by/4.0/.

\section{References}

1. Marie P, Sainton P. Sur la dysostose cleido-cranienne herediataire, Rev. neurol. 6:835, 1898. On hereditary cleido-cranial dysostosis. Clin Orthop Relat Res. 1968;58:5-7.

2. Yoshida T, Kanegane H, Osato M, Yanagida T, Miyawaki T, Ito Y, Shigesada K. Functional analysis of RUNX2 mutations in Japanese patients with cleidocranial dysplasia demonstrates novel genotype-phenotype correlations. Am J Hum Genet. 2002;71:724-38.

3. Ishii K, Nielsen IL, Vargervik K. Characteristics of jaw growth in cleidocranial dysplasia. Cleft Palate-Craniofac J. 1998;35:161-6.

4. Jensen BL, Kreiborg S. Dental treatment strategies in cleidocranial dysplasia. Br Dent J. 1992;172:243-7.

5. Komori T, Yagi H, Nomura S, Yamaguchi A, Sasaki K, Deguchi K, Shimizu Y, Bronson Y, Gao H, Inada M, Sato M, Okamoto R, Kitamura Y, Yoshiki S, Kishimoto T. Targeted disruption of Cbfa1 results in a complete lack of bone formation owing to maturational arrest of osteoblasts. Cell. 1997;89:755-64.

6. Mundlos S, Otto F, Mundlos C, Mulliken JB, Aylsworth AS, Albright S, Lindhout D, Cole WG, Henn W, Knoll JH, Owen MJ, Mertelsmann R, Zabel BU, Olsen BR. Mutations involving the transcription factor CBFA1 cause cleidocranial dysplasia. Cell. 1997;89:773-9.

7. Otto F, Thornell AP, Crompton T, Denzel A, Gilmour KC, Rosewell IR, Stamp GW, Beddington RS, Mundlos S, Olsen BR, Selby PB, Owen MJ. Cbfa1, a candidate gene for cleidocranial dysplasia syndrome, is essential for osteoblast differentiation and bone development. Cell. 1997;89:765-71.

8. Komori T. Runx2, an inducer of osteoblast and chondrocyte differentiation. Histochem Cell Biol. 2018;149:313-23.

9. Enomoto $\mathrm{H}$, Enomoto-Iwamoto $\mathrm{M}$, Iwamoto $\mathrm{M}$, Nomura S, Himeno M, Kitamura Y, Kishimoto T, Komori T. Cbfa1 is a positive regulatory factor in chondrocyte maturation. J Biol Chem. 2000;275:8695-702.

10. Takeda S, Bonnamy JP, Owen MJ, Ducy P, Karsenty G. Continuous expression of $\mathrm{Cbfa} 1$ in nonhypertrophic chondrocytes uncovers its ability to induce hypertrophic chondrocyte differentiation and partially rescues Cbfa1-deficient mice. Genes Dev. 2001;15:467-81.

11. Ueta C, Iwamoto M, Kanatani N, Yoshida C, Liu Y, EnomotoIwamoto M, Ohmori T, Enomoto H, Nakata K, Takada K, Kurisu K, Komori T. Skeletal malformations caused by overexpression of $\mathrm{Cbfa} 1$ or its dominant negative form in chondrocytes. J Cell Biol. 2001;153:87-100.

12. Komori T. Molecular mechanism of Runx2-dependent bone development. Mol Cells. 2020;43:168-75.

13. Kagoshima H, Shigesada K, Satake M, Ito Y, Miyoshi H, Ohki M, Pepling M, Gergen P. The Runt domain identifies a new family of heteromeric transcriptional regulators. Trends Genet. 1993;9:338-41.

14. Yoshida CA, Furuichi T, Fujita T, Fukuyama R, Kanatani N, Kobayashi S, Satake M, Takada K, Komori T. Core-binding factor beta interacts with Runx 2 and is required for skeletal development. Nat Genet. 2002;32:633-8.

15. Jaruga A, Hordyjewska E, Kandzierski G, Tylzanowski P. Cleidocranial dysplasia and RUNX2-clinical phenotype-genotype correlation. Clin Genet. 2016;90:393-402.

16. Quack I, Vonderstrass B, Stock M, Aylsworth AS, Becker A, Brueton L, Lee PJ, Majewski F, Mulliken JB, Suri M, Zenker M, Mundlos S, Otto F. Mutation analysis of core binding factor A1 in patients with cleidocranial dysplasia. Am J Hum Genet. 1999;65:1268-78.

17. Lee B, Thirunavukkarasu K, Zhou L, Pastore L, Baldini A, Hecht J, Geoffroy V, Ducy P, Karsenty G. Missense mutations abolishing DNA binding of the osteoblast-specific transcription factor OSF2/ CBFA1 in cleidocranial dysplasia. Nat Genet. 1997;16:307-10.

18. Otto F, Kanegane H, Mundlos S. Mutations in the RUNX2 gene in patients with cleidocranial dysplasia. Hum Mutat. 2002;19:209-16.

19. Lee KE, Seymen F, Ko J, Yildirim M, Tuna EB, Gencay K, Kim JW. RUNX2 mutations in cleidocranial dysplasia. Genet Mol Res. 2013;12:4567-74.

20. Morrison NA, Stephens AA, Osato M, Polly P, Tan TC, Yamashita N, Doecke JD, Pasco J, Fozzard N, Jones G, Ralston SH, Sambrook PN, Prince RL, Nicholson GC. Glutamine repeat variants in human RUNX2 associated with decreased femoral neck BMD, broadband ultrasound attenuation and target gene transactivation. PLoS ONE. 2012;7:e42617.

21. Zhou G, Chen Y, Zhou L, Thirunavukkarasu K, Hecht J, Chitayat D, Gelb BD, Pirinen S, Berry SA, Greenberg CR, Karsenty $\mathrm{G}$, Lee B. CBFA1 mutation analysis and functional correlation with phenotypic variability in cleidocranial dysplasia. Hum Mol Genet. 1999;8:2311-6.

22. Yamasaki S, Hamada A, Akagi E, Nakatao H, Ohtaka M, Nishimura K, Nakanishi M, Toratani S, Okamoto T. Generation of cleidocranial dysplasia-specific human induced pluripotent stem cells in completely serum-, feeder-, and integrationfree culture. In Vitro Cell Dev Biol Animal. 2016;52:252-64. https://doi.org/10.1007/s11626-015-9968-x.

23. Okada M, Ikegawa S, Morioka M, Yamashita A, Saito A, Sawai H, Murotsuki J, Ohashi H, Okamoto T, Nishimura G, Imaizumi K, Tsumaki N. Modeling type II collagenopathy skeletal dysplasia by directed conversion and induced pluripotent stem cells. Hum Mol Genet. 2015;24:299-313.

24. Pretemer Y, Kawai S, Nagata S, Nishio M, Watanabe M, Tamaki S, Alev C, Yamanaka S, Xue JY, Wang Z, Fukiage K, Tsukanaka M, Futami T, Ikegawa S, Toguchida J. Differentiation of hypertrophic chondrocytes from human iPSCs for the in vitro modeling of chondrodysplasias. Stem Cell Rep. 2021;16:610-25.

25. Hamada A, Akagi E, Yamasaki S, Nakatao H, Obayashi F, Ohtaka M, Nishimura K, Nakanishi M, Toratani S, Okamoto T. Induction of integration-free human-induced pluripotent stem cells under serum- and feeder-free conditions. Int J Dev Biol. 2020;56:85-95. https://doi.org/10.1007/s11626-019-00412-w.

26. Sato JD, Kawamoto T, Okamoto T. Cholesterol requirement of P3-X63-Ag8 and X63-Ag8.653 mouse myeloma cells for growth in vitro. J Exp Med. 1987;165:1761-6.

27. Nishimura K, Sano M, Ohtaka M, Furuta B, Umemura Y, Nakajima Y, Ikehara Y, Kobayashi T, Segawa H, Takayasu S, Sato H, Motomura K, Uchida E, Kanayasu-Toyoda T, Asashima M, Nakauchi H, Yamaguchi T, Nakanishi M. Development of defective and persistent Sendai virus vector: a unique gene delivery/expression system ideal for cell reprogramming. J Biol Chem. 2011;286:4760-71. https://doi.org/10.1074/jbc.M110. 183780.

28. Furue MK, Jackson J, Na JP, Okamoto T, Jones M, Baker D, Hata R, Moore HD, Sato JD, Andrews PW. Heparin promotes the growth of human embryonic stem cells in a defined serum-free 
medium. Proc Natl Acad Sci USA. 2008;105:13409-14. https:// doi.org/10.1073/pnas.0806136105.

29. Yamasaki S, Nabeshima K, Sotomaru Y, Taguchi Y, Mukasa H, Furue MK, Sato JD, Okamoto T. Long-term serial cultivation of mouse induced pluripotent stem cells in serum-free and feederfree defined medium. Int J Dev Biol. 2013;57:715-24. https://doi. org/10.1387/ijdb.130173to.

30. Ohnuma K, Fujiki A, Yanagihara K, Tachikawa S, Hayashi Y, Ito Y, Onuma Y, Chan T, Michiue T, Furue MK, Asashima M. Enzyme-free passage of human pluripotent stem cells by controlling divalent cations. Sci Rep. 2014;4:4646. https://doi.org/10. 1038/srep04646.

31. Hayashi Y, Chan T, Warashina M, Fukuda M, Ariizumi T, Okabayashi K, Takayama N, Otsu M, Eto K, Furue MK, Michiue T, Ohnuma K, Nakauchi H, Asashima M. Reduction of N-glycolylneuraminic acid in human induced pluripotent stem cells generated or cultured under feeder- and serum-free defined conditions. PLoS ONE. 2010;5: e14099. https://doi.org/10.1371/journal.pone. 0014099.

32. Yamasaki S, Taguchi Y, Shimamoto A, Mukasa H, Tahara H, Okamoto T. Generation of human induced pluripotent stem (iPS) cells in serum- and feeder-free defined culture and TGF-beta1 regulation of pluripotency. PLoS ONE. 2014;9: e87151. https:// doi.org/10.1371/journal.pone.0087151.

33. Yamashita A, Morioka M, Kishi H, Kimura T, Yahara Y, Okada M, Fujita K, Sawai H, Ikegawa S, Tsumaki N. Statin treatment rescues FGFR3 skeletal dysplasia phenotypes. Nature. 2014;513:507-11.

34. Bi W, Deng JM, Zhang Z, Behringer RR, de Crombrugghe B. Sox9 is required for cartilage formation. Nat Genet. 1999;22:85-9. https://doi.org/10.1038/8792.

35. Nykamp K, Anderson M, Powers M, Garcia J, Herrera B, Ho YY, Kobayashi Y, Patil N, Thusberg J, Westbrook M, Topper S.
Sherloc: a comprehensive refinement of the ACMG-AMP variant classification criteria. Genet Med. 2017;19:1105-17. https://doi. org/10.1038/gim.2017.37.

36. Choi JY, Pratap J, Javed A, Zaidi SK, Xing L, Balint E, Dalamangas S, Boyce B, van Wijnen AJ, Lian JB, Stein JL, Jones $\mathrm{SN}$, Stein GS. Subnuclear targeting of Runx/Cbfa/AML factors is essential for tissue-specific differentiation during embryonic development. Proc Natl Acad Sci USA. 2001;98:8650-5. https:// doi.org/10.1073/pnas.151236498.

37. Jensen BL, Kreiborg S. Development of the dentition in cleidocranial dysplasia. J Oral Pathol Med. 1990;19:89-93. https://doi.org/ 10.1111/j.1600-0714.1990.tb00803.x.

38. Tsuji M, Suzuki H, Suzuki S, Moriyama K. Three-dimensional evaluation of morphology and position of impacted supernumerary teeth in cases of cleidocranial dysplasia. Congenital Anom. 2020;60:106-14. https://doi.org/10.1111/cga.12358.

39. Togo Y, Takahashi K, Saito K, Kiso H, Tsukamoto H, Huang B, Yanagita M, Sugai M, Harada H, Komori T, Shimizu A, MacDougall M, Bessho K. Antagonistic functions of USAG-1 and RUNX2 during tooth development. PLoS ONE. 2016;11: e0161067. https://doi.org/10.1371/journal.pone.0161067.

40. Murashima-Suginami A, Kiso AH, Tokita Y, Mihara E, Nambu Y, Uozumi R, Tabata Y, Bessho K, Takagi J, Sugai M, Takahashi K. Anti-USAG-1 therapy for tooth regeneration through enhanced BMP signaling. Sci Adv. 2021;2021:7. https://doi.org/10.1126/ sciadv.abf1798.

Publisher's Note Springer Nature remains neutral with regard to jurisdictional claims in published maps and institutional affiliations. 